\title{
Longitudinal stability of blood eosinophil count strata in the COPD COSYCONET cohort
}

This article was published in the following Dove Press journal:

International Journal of COPD

\author{
Timm Greulich' \\ Sina Mager' \\ Tanja Lucke ${ }^{2}$ \\ Andreas Rembert Koczulla' \\ Robert Bals ${ }^{3}$ \\ Sebastian Fähndrich ${ }^{3}$ \\ Rudolf A Jörres² \\ Peter Alter' \\ Anne Kirsten ${ }^{4}$ \\ Claus Franz Vogelmeier \\ Henrik Watz ${ }^{4}$ \\ 'Department of Medicine, Pulmonary \\ and Critical Care Medicine, \\ University Medical Centre Giessen \\ and Marburg, Philipps-University, \\ Member of the German Centre \\ for Lung Research (DZL), Marburg, \\ Germany; ${ }^{2}$ Institute and Outpatient \\ Clinic for Occupational, Social and \\ Environmental Medicine Ludwig- \\ Maximilians-Universität München, \\ Munich, Germany; ${ }^{3}$ Department of \\ Internal Medicine V, Pulmonology, \\ Allergology, Respiratory and Intensive \\ Care Medicine, Saarland Hospital, \\ Homburg/Saar, Germany; ${ }^{4}$ Pulmonary \\ Research Institute at Lungen Clinic \\ Grosshansdorf, Airway Research \\ Center North (ARCN), Member \\ of the German Centre for Lung \\ Research (DZL), Grosshansdorf, \\ Germany
}

Correspondence: Timm Greulich Department of Medicine, Pulmonary and Critical Care Medicine, University Medical Centre Giessen and Marburg, Philipps-University, Baldingerstraße, Marburg 35043, Germany Email greulich@med.uni-marburg.de

\section{Introduction}

It has been increasingly recognized that the numbers of blood eosinophils (eos) might be an important biomarker in patients with COPD to identify patients at risk for exacerbations and for treatment to inhaled corticosteroid (ICS) treatment or anti-interleukin-5 therapy. ${ }^{1-3}$ However, data about the stability of blood eos counts over time are rare. We used data from the multicenter COSYCONET study to analyze the variability of eos by strata over a period of 18 months. ${ }^{4}$

\section{Methods}

The German COPD and Systemic Consequences-Comorbidities Network (COSYCONET) cohort study is a multicenter, longitudinal, prospective, observational study, into which 2,741 patients with the diagnosis of COPD were recruited between 2010 and 2013 in 31 study centers throughout Germany. ${ }^{4}$ Eos were collected in a number of centers as part of routine clinical assessments. To determine the longitudinal stability of their counts, we included all patients in whom a differential blood cell count was available at the study visits V1-V3 (baseline, 6 months, 18 months). These 334 patients were more prone to exacerbations and were more likely to have an ICS-containing treatment regimen than the remaining part of the COSYCONET population (Table 1).

First, we determined the absolute number and proportion of patients, who exhibited eos of $<150$ cells $/ \mu \mathrm{L}$ (rated as non-eosinophilic), 150-299 cells $/ \mu \mathrm{L}$ (intermediate), and $\geq 300 \mathrm{cell} / \mathrm{s} / \mu \mathrm{L}$ (eosinophilic) at visit 1 . Next, we analyzed the longitudinal stability of the three strata from visit 1 to visit 2, and from visit 2 to visit 3 . Finally, we displayed the results in analogy to the stability analysis performed by Hurst for the susceptibility to exacerbations. ${ }^{5}$

\section{Results}

At visit 1, 165 patients (50\%) were non-eosinophilic, 121 (36\%) intermediate, and 48 (14\%) eosinophilic. The overall distribution remained fairly stable over time (visit 2: $43 \%, 40 \%, 18 \%$, respectively; visit 3: 46\%, 40\%, 14\%, respectively). The changes between strata over consecutive visits and the resulting distributions are shown in Figure 1. Putting the data from the three visits together, $26 \%$ of patients 
Table I Baseline data from 334 patients in whom a differential blood cell blood count was available at visits VI-V3 as compared to 2,407 patients without differential blood cell count available at all time points VI-V3

\begin{tabular}{llll}
\hline & $\begin{array}{l}\text { Current } \\
\text { study } \\
\text { population }\end{array}$ & $\begin{array}{l}\text { Residual } \\
\text { COSYCONET } \\
\text { population }\end{array}$ & $\begin{array}{l}P_{\text {-value }} \\
\text { NA }\end{array}$ \\
\hline $\mathrm{n}$ & 334 & 2.407 & 0.12 \\
Age, years & $64.37 \pm 8.33$ & $65.15 \pm 8.66$ & 0.1 \\
Male, \% & 63.2 & 58.5 & 0.1 \\
BMI, kg/m $m^{2}$ & $27.49 \pm 5.41$ & $26.97 \pm 5.38$ & 0.2 \\
FEV,$\%$ predicted & $55.5 \pm 17.97$ & $57.11 \pm 21.63$ & 0.77 \\
FEV, I & $1.66 \pm 0.64$ & $1.67 \pm 0.73$ & $<0.001$ \\
No of exacerbations previous year & $1.85 \pm 4.57$ & $1.21 \pm 2.24$ & 0.09 \\
6-MWD, min & $429 \pm 98.42$ & $418.95 \pm 109.83$ & 0.16 \\
BODE & $2.1 \pm 1.88$ & $2.27 \pm 2.01$ & 0.69 \\
SGRQ & $43.09 \pm 19.69$ & $42.63 \pm 20.03$ & 0.03 \\
ICS-containing treatment, \% & 57.8 & 63.9 & 0.45 \\
History of asthma, \% & 20.1 & 18.4 & \\
\hline
\end{tabular}

Notes: Data are displayed as mean \pm SD. ${ }^{\text {t}}$-test was calculated for continuous variables, Fisher's exact test was calculated for dichotomous variables.

Abbreviations: NA, not applicable; BMI, body mass index; FEV , forced expiratory volume in I second; 6-MWD, 6-minute walking distance; BODE, score based on body mass index, obstruction, dyspnea, Exercise capacity; SGRQ, St George's Respiratory Questionnaire; ICS, inhaled corticosteroid.

were persistently non-eosinophilic $(<150$ eos $/ \mu \mathrm{L})$, which implies that $74 \%$ exhibited $\geq 150 \mathrm{eos} / \mu \mathrm{L}$ at least at one occasion. Conversely, $28 \%$ exhibited $\geq 300$ eos $/ \mu \mathrm{L}$ at least once within 18 months, but only $5 \%$ of patients were persistently eosinophilic ( $\geq 300 \mathrm{eos} / \mu \mathrm{L})$ at all three study visits. Excluding patients whose status regarding corticosteroid treatment (on/off) changed from one visit to another $(\mathrm{n}=63)$ did not change the results significantly (data not shown).

\section{Discussion}

The main findings of this analysis are (1) that $26 \%$ of COPD patients in the study cohort were persistently noneosinophilic, (2) $5 \%$ were persistently eosinophilic, and (3) $28 \%$ exhibited $\geq 300$ eos $/ \mu \mathrm{L}$ at least once in three observations over a period of 18 months.

Few longitudinal studies evaluated the robustness of eos strata in COPD before. ${ }^{6,7}$ Oshagbemi et al found the stability of counts higher in patients showing $<340$ eos/ $\mu \mathrm{L}$ compared to patients showing $\geq 340$ eos $/ \mu \mathrm{L} .{ }^{6} \mathrm{Using}$ a lower cut-off level of $2 \%$, Singh et al observed that the majority of patients showed variations around a value of $2 \%{ }^{7}$ When defining three different strata in absolute eos numbers, we observed that among those that were robust over time the non-eosinophilic stratum $(<150$ eos/ $\mu \mathrm{L}$ ) was the most frequent one. Still it comprised only about one quarter of the population, while the majority of patients were in the intermediate or high eosinophilic group at least at one occasion. More than one quarter of the population exhibited $\geq 300 \mathrm{eos} / \mu \mathrm{L}$ at least once in three visits.

Even though our data may not be fully representative for the entire COSYCONET cohort (eg, higher exacerbation rate, higher percentage of patients on any ICS-containing regimen) and some groups at visit 3 included a small number of patients (making the results somewhat preliminary), they help to assess the stability of the eos signal, which will potentially be used in the future to come to treatment decisions.

\section{Conclusion}

Our analysis demonstrates that in COPD non-eosinophilia in blood is more robust over time than eosinophilia defined as count $\geq 300 \mathrm{eos} / \mu \mathrm{L}$. These observations might be helpful for the design of studies that address the question, whether rational and effective treatment decisions should better refer to persistent or to occasional eosinophilia. 
Visit 1

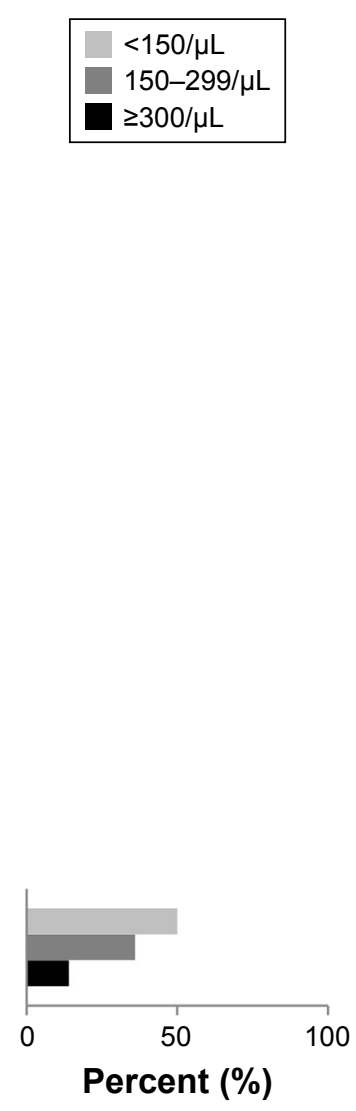

Visit 2

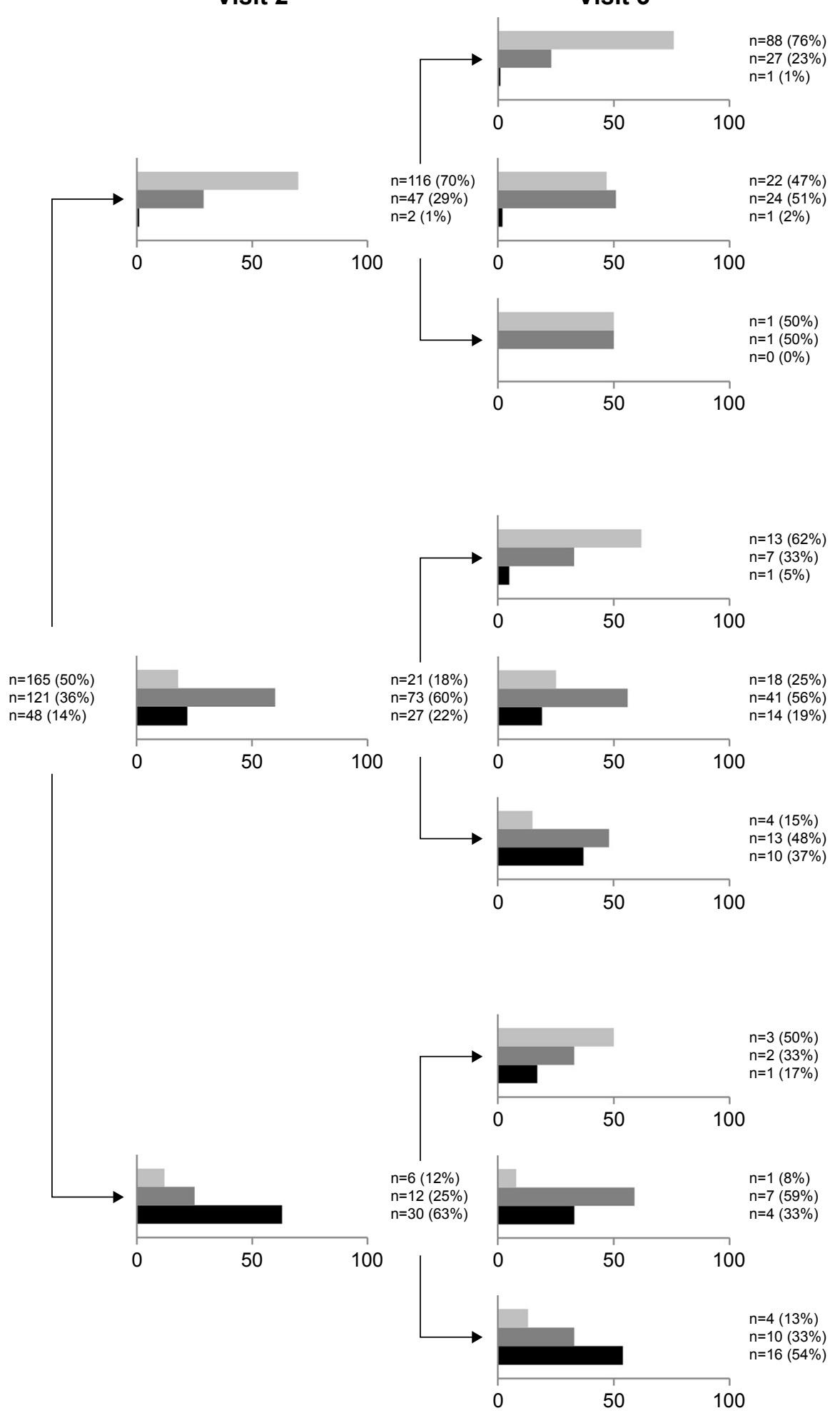

Figure I Absolute number and proportion of patients according to blood eos count at visits I, 2, and 3.

Note: The proportions of participants at visit one are sequentially subdivided according to their eos blood count at visit 2 , and the proportions of patients at visit 2 are sequentially subdivided according to their eos blood count at visit 3 .

Abbreviation: eos, eosinophil. 


\section{Disclosure}

Dr T Greulich reports personal fees from AstraZeneca, Boehringer Ingelheim, Chiesi, CSL-Behring, GlaxoSmithKline, Grifols, MedUpdate, Mundipharma, and Novartis. S Mager and Dr T Lucke report no conflicts of interest. Professor Dr AR Koczulla reports grants from Boehringer-Ingelheim, Astra Zeneca, Novartis, Grifols, CSCSL, Roche, Teva, BerlinChemie, Chiesi und Novotec, outside the submitted work. Professor Dr R Bals reports grants from BMBF, AstraZeneca $\mathrm{GmbH}$, Bayer Schering Pharma AG, Boehringer Ingelheim Pharma GmbH \& Co. KG, Chiesi GmbH, GlaxoSmithKline, Grifols Deutschland GmbH, MSD Sharp \& Dohme GmbH, Mundipharma GmbH, Novartis Deutschland GmbH, Pfizer Pharma GmbH, Takeda Pharma Vertrieb GmbH \& Co. KG., during the conduct of the study; as well as grants from Wilhelm-Sander-Stiftung, grants from Deutsche Krebshilfe and grants from Schwiete-Stiftungoutside the submitted work. Dr S Fähndrich reports grants from Grifols, CSL Behring, and AstraZeneca, outside the submitted work. Dr RA Jörres reports grants from Federal Ministry of Education and Research (grant number 01GI0881, 01GI0882), during the conduct of the study. Professor Dr P Alter reports grants from German Federal Ministry of Education and Research (BMBF) Competence Network Asthma and COPD (ASCONET), grants from AstraZeneca $\mathrm{GmbH}$, grants and non-financial support from Bayer Schering Pharma AG, grants, personal fees and non-financial support from Boehringer Ingelheim Pharma $\mathrm{GmbH} \& \mathrm{Co} . \mathrm{KG}$, grants and non-financial support from Chiesi GmbH, grants from GlaxoSmithKline, grants from Grifols Deutschland GmbH, grants from MSD Sharp \& Dohme $\mathrm{GmbH}$, grants and personal fees from Mundipharma $\mathrm{GmbH}$, grants, personal fees and non-financial support from Novartis
Deutschland GmbH, grants from Pfizer Pharma GmbH, grants from Takeda Pharma Vertrieb GmbH \& Co. KG, outside the submitted work. Dr AM Kirsten reports personal fees from Astra Zeneca and Boehringer Ingelheim, outside the submitted work. Professor Dr CF Vogelmeier reports grants from AstraZeneca, Boehringer Ingelheim, CSL Behring, Chiesi, GlaxoSmithKline, Grifols, Menarini, Mundipharma, Novartis, Teva, Cipla, Omniamed, and MedUpdate. Dr H Watz reports personal fees from AstraZeneca, personal fees from Takeda, personal fees from BerlinChemie, personal fees from BoehringerIngelheim, personal fees from Chiesi, personal fees from Novartis, personal fees from GlaxoSmithKline, personal fees from Roche, outside the submitted work. The authors report no other conflicts of interest in this work.

\section{References}

1. Bafadhel M, Pavord ID, Russell REK. Eosinophils in COPD: just another biomarker? Lancet Respir Med. 2017;5(9):747-759.

2. Watz H, Tetzlaff $\mathrm{K}$, Wouters EF, et al. Blood eosinophil count and exacerbations in severe chronic obstructive pulmonary disease after withdrawal of inhaled corticosteroids: a post-hoc analysis of the WISDOM trial. Lancet Respir Med. 2016;4(5):390-398.

3. Pavord ID, Chanez P, Criner GJ, et al. Mepolizumab for eosinophilic chronic obstructive pulmonary disease. $N$ Engl J Med. 2017;377(17): 1613-1629.

4. Karch A, Vogelmeier C, Welte T, et al. The German COPD cohort COSYCONET: aims, methods and descriptive analysis of the study population at baseline. Respir Med. 2016;114:27-37.

5. Hurst JR, Vestbo J, Anzueto A, et al. Susceptibility to exacerbation in chronic obstructive pulmonary disease. $N$ Engl J Med. 2010;363(12): $1128-1138$.

6. Oshagbemi OA, Burden AM, Braeken DCW, et al. Stability of blood eosinophils in patients with chronic obstructive pulmonary disease and in control subjects, and the impact of sex, age, smoking, and baseline counts. Am J Respir Crit Care Med. 2017;195(10):1402-1404.

7. Singh D, Kolsum U, Brightling CE, et al. Eosinophilic inflammation in COPD: prevalence and clinical characteristics. Eur Respir J. 2014; 44(6):1697-1700.
International Journal of COPD

\section{Publish your work in this journal}

The International Journal of COPD is an international, peer-reviewed journal of therapeutics and pharmacology focusing on concise rapid reporting of clinical studies and reviews in COPD. Special focus is given to the pathophysiological processes underlying the disease, intervention programs, patient focused education, and self management protocols.

\section{Dovepress}

This journal is indexed on PubMed Central, MedLine and CAS. The manuscript management system is completely online and includes a very quick and fair peer-review system, which is all easy to use. Visit $\mathrm{http}: / /$ www.dovepress.com/testimonials.php to read real quotes from published authors. 